\title{
Dimension and Bridging Ligand Effects on Mo-mediated Catalytic Transformation of Dinitrogen to Ammonia: Chain-like Extended Models of Nishibayashi's Catalyst
}

Xiao-Lan Sheng ${ }^{\text {a }}$, Enrique R Batista ${ }^{\mathrm{b}}$, Yi-Xiang Duan ${ }^{\mathrm{a}}$, Yong-Hui Tian ${ }^{*}$ a

${ }^{a}$ College of Life Sciences, Research Center of Analytical Instrumentation, Sichuan University, Chengdu, Sichuan 610064, P. R. China

${ }^{b}$ Theoretical Division, Los Alamos National Laboratory (LANL), Los Alamos, New Mexico 87545, United States

*Corresponding Author: yonghuitian@scu.edu.cn.

ABSTRACT: Previous studies suggested that in Nishibayashi's homogenous catalytic systems based on molybdenum (Mo) complexes, the bimetallic structure facilitated dinitrogen to ammonia conversion in comparison to the corresponding monometallic complexes, likely due to the through-bond interactions between the two Mo centers. However, more detailed model systems are necessary to support this bimetallic hypothesis, and to elucidate the multi-metallic effects on the catalytic mechanism. In this work, we computationally examined the effects of dimension as well as the types of bridging ligands on the catalytic activities of molybdenum-dinitrogen complexes by using a set of extended model systems based on Nishibayashi's bimetallic structure. The polynuclear chains containing four $\left([\mathrm{Mo}]_{4}\right)$ or more Mo centers were found to drastically enhance the catalytic performance by comparing with both the monometallic and bimetallic complexes. Carbide $\left([: \mathrm{C} \equiv \mathrm{C}:]^{2-}\right)$ was found to be a more effective bridging ligand than $\mathrm{N}_{2}$ in terms of electronic charges dispersion between metal centers thereby facilitating reactions in the catalytic cycle. The mechanistic modelling suggests that in principle, more efficient catalytic system for $\mathrm{N}_{2}$ to $\mathrm{NH}_{3}$ transformation might be obtained by extending the polynuclear chain to a proper size in combination with an effective bridging ligand for charge dispersion. 
Keywords: Nitrogen fixation; Catalysis; Molybdenum complex; Polynuclear model; DFT.

\section{Introduction}

Dinitrogen $\left(\mathrm{N}_{2}\right)$ is the most abundant molecule in earth's atmosphere. However, $\mathrm{N}_{2}$ exists as an inert molecule due to its nonpolar nature and stability $[1,2]$ making it difficult to participate in chemical reactions. Industrially, the conversion of dinitrogen to ammonia $\left(\mathrm{NH}_{3}\right)$ mainly relies on the Haber-Bosch process [3], which requires harsh reaction conditions $\left(350-550^{\circ} \mathrm{C}\right.$ under the pressure of 150-350 atm) and is energy extensive. In contrast, nitrogenase enzyme can reduce $\mathrm{N}_{2}$ to $\mathrm{NH}_{3}$ at ambient temperature and pressure. It has been recognized that in the biological $\mathrm{N}_{2}$ fixation systems, the dinitrogen reduction is accomplished on a cluster structure called iron-molybdenum cofactor [4-6] .

Inspired by the biological systems, tremendous efforts have been devoted to the synthesis of metallocomplexes [7-15] facilitating dinitrogen reduction in the presence of electron and proton sources under ambient conditions. Chatt pioneered in the development of transition-metal dinitrogen complexes with well-defined structures, and the first $\mathrm{N}_{2}$ reduction to $\mathrm{NH}_{3}$ was observed with quantitative conversion based on $\left[\mathrm{M}\left(\mathrm{N}_{2}\right)_{2}\left[\mathrm{PR}_{3}\right]_{4}\right](\mathrm{M}=\mathrm{Mo}$ or $\mathrm{W} ; \mathrm{R}=$ alkyl or aryl $)$ complex $[16,17]$. Subsequently, the preparation of various transition-metal dinitrogen complexes and the transformation of the coordinated dinitrogen into nitrogenous compounds, especially $\mathrm{NH}_{3}$, have been achieved at mild reaction conditions [18-26]. Although plenty of studies on the stoichiometric reactivity of transition metal-dinitrogen complexes have been reported, the cases for catalytic conversion from $\mathrm{N}_{2}$ to $\mathrm{NH}_{3}$ are rare [27-31]. In 2003, the first catalytic system of $\mathrm{N}_{2}$ to $\mathrm{NH}_{3}$ transformation under ambient conditions was prepared by Yandulov and Schrock [23] 
using a molybdenum complex as shown in Chart 1a, which is featured by a single metal center $\left(\left[\mathrm{HIPTN} \mathrm{N}_{3} \mathrm{~N}\right]-\mathrm{Mo}\left(\mathrm{N}_{2}\right)\right)$ supported by a triamidoamine ligand, where HIPT = $\left\{3,5-\left(2,4,6-\mathrm{iPr}_{3} \mathrm{C}_{6} \mathrm{H}_{2}\right)_{2} \mathrm{C}_{6} \mathrm{H}_{3}\right\}$. After that in 2011, the second Mo-containing system capable of catalytic conversion of $\mathrm{N}_{2}$ into $\mathrm{NH}_{3}$ was proposed by Nishibayashi and coworkers [24], from which a 23 equivalents of ammonia were obtained in terms of the catalyst (Chart 1b). In addition to the Mo-based catalysts, Anderson et al. proposed tris(phosphine)borane and tri(phosphine)alkyl supported iron complexes that could mediate the $\mathrm{N}_{2}$ reduction to $\mathrm{NH}_{3}$ in a catalytic mode $[25,26,32,33]$. Herein, we focus on the catalytic behaviors of Mo-based complexes, and hence a brief review is presented below about the reaction mechanism of the Mo-based homogeneous catalytic systems.

Chart 1. Single-Molybdenum (Schrock) and Di-Molybdenum (Nishibayashi) Complexes

a

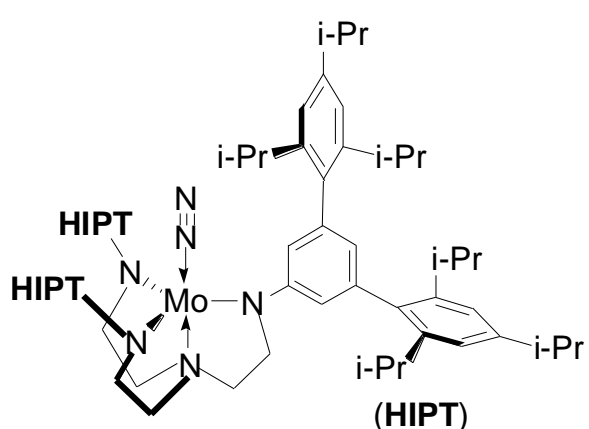

b

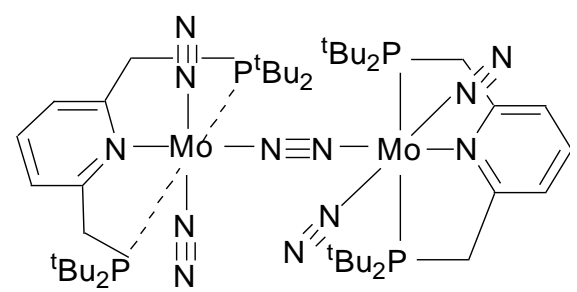

In Nishibayashi's catalytic system, a binuclear Mo-complex was used, which is featured by two Mo atoms bridged by a dinitrogen ligand (Chart 1b). Previous mechanistic studies [34-36] have shown that the reaction processes in Nishibayashi's bimetallic system and Schrock's monometallic system basically follow the similar reaction mechanism as originally proposed by Chatt. In this route called distal (or asymmetric) pathway, a nitride intermediate is produced with the release of a $\mathrm{NH}_{3}$ as a result of sequential addition of $\mathrm{H}$ atoms on a single nitrogen atom of a terminal $\mathrm{N}_{2}$ ligand. However, upon a closer comparative inspection of the above two 
Mo-complex catalysts, it can be recognized that they distinguish from each other mainly in two aspects. Firstly, the metal atom is in Mo(III) for Schrock's monometallic complex, in contrast to Mo(0) as in Nishibayashi's dimetallic complex. Secondly and also most importantly, the bimetallic complex is structurally characterized by two metal centers bridged with a dinitrogen ligand. Although the Schrock's mononuclear Mo(III) complex shows catalytic effect, the $\mathrm{N}_{2}$ to $\mathrm{NH}_{3}$ conversion is difficult for the Chatt's $\mathrm{Mo}(0)$ complexes, and only quantitative formation of $\mathrm{NH}_{3}$ was achieved $[37,38]$. On the other hand, as in Nishibayashi's system, the bimetallic Mo(0)-complexes are capable of catalytically transforming $\mathrm{N}_{2}$ into $\mathrm{NH}_{3}$. In Nishibayashi's bimetallic $\mathrm{Mo}(0)$-complex as shown in Chart $1 \mathrm{~b}$, the $\mathrm{N}_{2}$ bridging ligand not only "mechanically" holds the two $\operatorname{Mo}(0)$ atoms forming a dimer, but also provides a channel between the two metal centers for electronic communication. According to recent theoretical studies,[34, 35] the bimetallic structure is likely to favor the charge delocalization on the two metal atoms upon proton addition on a terminal $\mathrm{N}_{2}$ ligand. That explains why a bimetallic structure is necessary for the occurrence of catalytic dinitrogen reduction to ammonia in Nishibayashi's system. However, we envisage that the introduced electronic charges upon protonation are still very spatially confined in Nishibayashi's complex containing only two Mo atoms bridged by a $\mathrm{N}_{2}$ ligand. The catalytic activity of Nishibayashi's bimetallic complex suggests that a chain-like extension by including more metal centers in polynuclear complexes would improve the catalytic performance of Mo-complexes for $\mathrm{N}_{2}$ transformation to $\mathrm{NH}_{3}$.

In this report, we carried out an extensive exploration of dimensional effect on the catalytic performance of Mo-complexes for dinitrogen reduction. For this purpose, we systematically investigated a series of model complexes containing multimetallic centers bridged by dinitrogen 
ligands structurally analogous to Nishibayashi's bimolybdenum catalyst. With the model systems, we intended to demonstrate how the chain length of Mo-complexes affected the catalytic behaviors and the energy profiles. Moreover, the effect of bridging ligands was inspected. We suggest that with a proper bridging ligand such as carbide $[: \mathrm{C} \equiv \mathrm{C}:]^{2-}$, a more effective electronic channel can be established between the adjacent metal centers, which may considerably facilitate the overall reactions in terms of thermodynamics. The findings in this work may contribute to the mechanistic understanding of $\mathrm{N}_{2}$ to $\mathrm{NH}_{3}$ conversion catalyzed by organometallic complexes in homogeneous systems, and shed light on the principle for the design of efficient catalysts operated at ambient reaction conditions.

\section{Computational methods}

All geometries of the compounds in this paper were fully optimized with Becke's three parameter (B3) hybrid exchange functionals combined with Lee-Yang-Parr (LYP) correlation functionals (B3LYP) [39, 40], which is implemented in Gaussian 09 [41]. The 6-31G(d,p) basis set was used for $\mathrm{H}, \mathrm{C}, \mathrm{N}$, and $\mathrm{P}$, while for Mo, the Stuttgart effective core potential and the corresponding basis set were employed [42]. The same theory level was used for the energy calculations based on the optimized geometries. Single-point energy calculations with larger basis sets and different functionals predicted basically the same reaction trends as for B3LYP/6-31G(d,p) as shown in Fig. S1 in the Supplementary Information (SI). In addition, solvation effect in dichloroethane [43, 44] was accounted for using the solvation model based on density (SMD) scheme, in which the quantum mechanical charge density of a solute molecule interact with the solvent charges described by a continuum model $[45,46]$. 
The model complexes as described in Scheme 1 were constructed based on Nishibayashi's bimetallic complex (Chart $1 b)$. It is noteworthy that the tertiary butyl groups $\left({ }^{t} \mathrm{Bu}\right)$ of the tridentate pincer ligands as in the original Nishibayashi's complex (Chart 1b) were replaced with $\mathrm{H}$ atoms in the model structures to save computational cost, and the predicted trend of the calculated reaction energies should be very similar no matter $\mathrm{H}$, or ${ }^{t} \mathrm{Bu}$ is used [47]. In the model systems, we extended Nishibayashi's bimetallic complexes in one-dimension, and the polynuclear complexes thus obtained show a structural characteristic of a chain of metal centers bridged with $\mathrm{N}_{2}$ ligands. The model structures are represented with a general formula as depicted in Scheme 1, where $\mathrm{n}$ refers to the number of repeat unit consisting of a metal center and a bridging $\mathrm{N}_{2}$ ligand. For example, when $\mathrm{n}=1$ or 2 , a dimer or trimer structure is obtained containing two or three metal centers, respectively. One notes that the Mo represents moiety composed of a Mo atom and a pincer ligand (Chart 1b). (See Scheme S1 and Fig. S2 in the SI for the detailed structures). The chain length effect was examined in a range from one to five metal centers, beyond which we found that the dimensional effect reached saturation as will be shown in the following sections. Note that the model compounds involved are merely used for the purpose of mechanistic understanding of the catalytic properties, while their synthesis is not the focus in this study although plausible based on the bimolybdenum complexes existing in the literature [48-50].

Scheme 1. Structure of the Model Polynuclear Complex

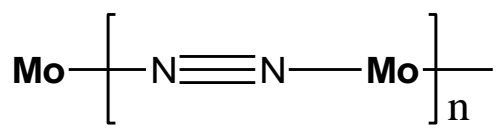


Considering the stronger coordination ability of carbide ligand bridge $[: \mathrm{C} \equiv \mathrm{C}:]^{2-}$ than that of $\mathrm{N}_{2}$ ligand [48], it may provide a more effective channel for electronic communications between Mo-centers thermodynamically in favor of the reaction steps in a catalytic cycle. Actually in the literature $[49,50]$, some molybdenum complexes can be found with bridging $[: C \equiv C:]^{2-}$ ligands. Therefore, in the model complexes, the replacement of $\mathrm{N}_{2}$ by carbide ligand is rational from the point of view of synthesis. It is noted that, the bridging ligands of $\mathrm{N} \equiv \mathrm{N}$ and $[: \mathrm{C} \equiv \mathrm{C}:]^{2-}$ are isoelectronic with each other, but the Mo atoms are in zero oxidation state in the $\mathrm{N}_{2}$ coordinated systems, in contrast to Mo(II) (located in the middle of the chains) or Mo(I) (terminal ones) in the model complexes with bridging carbide ligands.

\section{Results and discussion}

For convenience of discussion, we firstly present in Scheme 2 an overall view of the catalytic cycle computationally identified as the most favourable processes with respect to thermodynamics. As shown in Scheme 2, for all the model polynuclear complexes targeted in this study, the thermodynamically most accessible reaction pathway corresponds to the distal mechanism, in which the $\beta$-nitrogen in a terminal $\mathrm{N}_{2}$ ligand is first fully reduced, followed by hydrogenation of the vicinal nitrogen. This catalytic route is basically in agreement with the previously proposed reaction mechanism based on DFT calculations for the Nishibayashi's bimetallic catalyst [34]. We also note from a previous investigation that the bimetallic complexes dissociated in some steps of the catalytic cycle [35], which is based on indirect evidence of the capture of monometallic species with some molecular ligands. However, based on the very similar energetics of the corresponding monometallic or bimetallitic species, the bimetallic 
processes are possible in agreement with the previous DFT calculations [34]. The other possible reaction processes thermodynamically less accessible are summarized in Scheme S2 in the SI. In the next sections, the focus was placed on the favorable reaction steps in Scheme 2, which were based on the polynuclear model complexes.

Scheme 2. An Overall View of the Reaction Processes for $\mathrm{N}_{2}$ to $\mathrm{NH}_{3}$ Transformation Catalyzed by the Model Mo-Complexes ( $\mathrm{n}=1,2$ and 3) in the Presence of Proton and Electron Sources. X Represents N or C, and the Pincer Ligands Are Omitted for Clarity. Reactions with the Monometallic or Bimetallic Complexes Are Shown in Scheme S2.

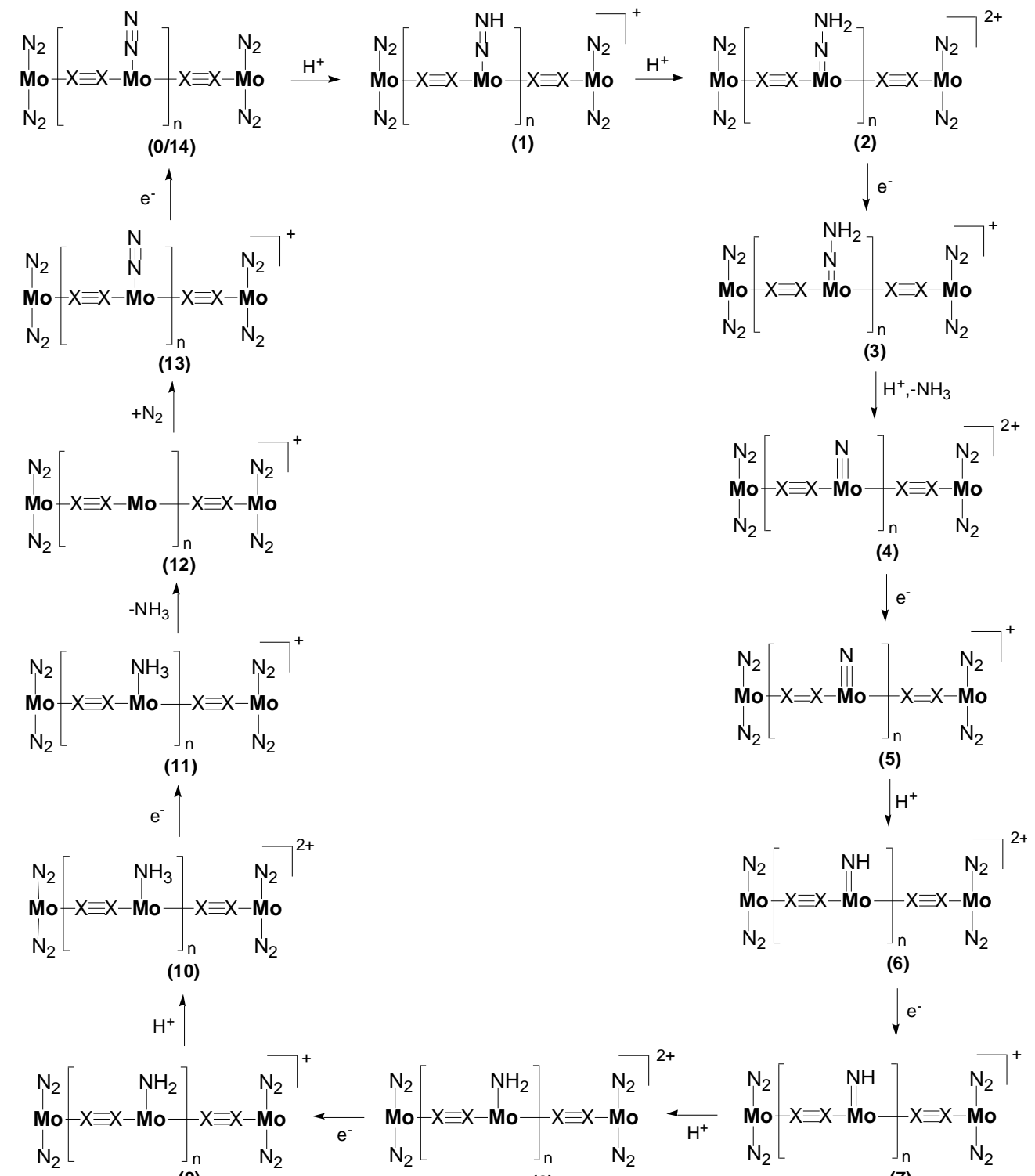

(9)

(8)

(7) 
In reaction Scheme $2,[\mathrm{LutH}]^{+}(\mathrm{Lut}=2,6$-dimethylpyridine) was used as the proton source denoted by " $\mathrm{H}^{+}$" [23], while $\mathrm{Co}\left(\mathrm{Cp}^{*}\right)_{2}\left(\mathrm{Cp}^{*}=1,2,3,4,5\right.$-pentamethylcyclopentadiene $)$ was used as the reducing agent represented by " $\mathrm{e}$ "”. The energies of the protonation and reduction steps were calculated according to Formula (1) and (2), respectively. [ $\left.\mathrm{MH}_{\mathrm{n}}\right]$ and $\left[\mathrm{MH}_{\mathrm{n}+1}\right](\mathrm{n}=0,1$ or 2) refer to the Mo complexes involving a proton transfer in Formula (1) or an electron transfer reaction in Formula (2), respectively. Similar to the previous DFT studies [51-54], the calculated electronic energies were used for the reaction energetic profiles in this study, which were calculated in low-spin states for all of the model compounds unless stated otherwise. In addition, the reaction enthalpy was calculated for the monometallic and bimetallic systems as presented in Fig. S3, which shows the similar trends corresponding to the electronic energies. In the calculated energetic profiles, the energy of the starting complex $\mathbf{0}$ (see Scheme 2) was used as the reference.

$$
\begin{aligned}
& {\left[\mathrm{MH}_{\mathrm{n}}\right]+[\mathrm{LutH}]^{+} \rightarrow\left[\mathrm{MH}_{\mathrm{n}+1}\right]^{+}+\text {Lut }} \\
& {\left[\mathrm{MH}_{\mathrm{n}+1}\right]^{+}+\left[\mathrm{Co}\left(\mathrm{Cp}^{*}\right)_{2}\right] \rightarrow\left[\mathrm{MH}_{\mathrm{n}+1}\right]+\left[\mathrm{Co}\left(\mathrm{Cp}^{*}\right)_{2}\right]^{+}}
\end{aligned}
$$

\section{Chain-like extension of the Nishibayashi bimetallic Mo-complex with $\mathrm{N}_{2}$ bridging ligand}

As shown in Chart $1 \mathrm{~b}$, the Nishibayashi bimetallic complex is featured with two Mo centers bridged by a $\mathrm{N}_{2}$ ligand. Following such a structural characteristic, a set of polynuclear complexes were constructed by extending the Nishibayashi's bimetallic structure, where the Mo atoms were bridged by $\mathrm{N}_{2}$ ligands forming chains as displayed in Scheme 1. In the following descriptions, the structures of the related polynuclear model complexes are denoted by $[\mathrm{Mo}]_{\mathrm{n}}$ for ease of description with $\mathrm{n}$ referring to the number of metal atoms. On the basis of DFT calculations, the 
reaction energy profiles of $\mathrm{N}_{2}$ reduction to $\mathrm{NH}_{3}$ catalyzed by the set of model complexes are presented in Fig. 1.

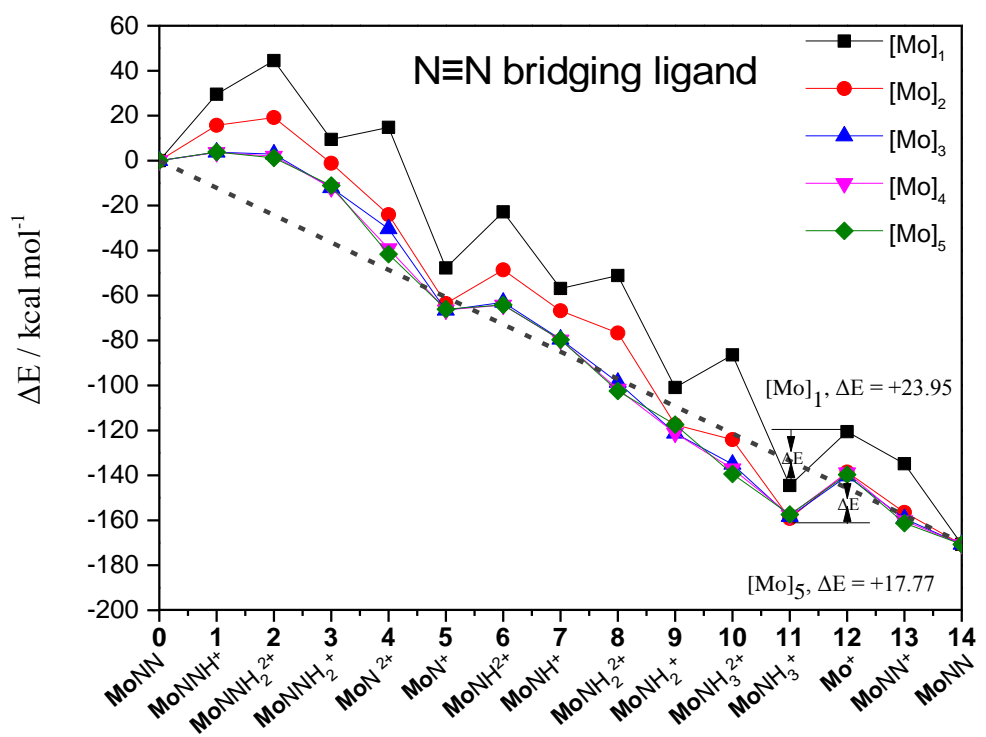

Fig. 1 The energetic profiles for $\mathrm{N}_{2}$ to $\mathrm{NH}_{3}$ transformation catalyzed by a set of $\mathrm{N}_{2}$-bridged model complexes containing different number of Mo atoms denoted by $[\mathrm{Mo}]_{\mathrm{n}}$. An imaginary dash line was added connecting $\mathrm{N}_{2}$ and $\mathrm{NH}_{3}$ on the profiles, and the energy difference between them was determined by the proton and electron sources used.

Before detailed discussion, a general description was presented for the reactions along a sequential protonation and reduction processes for $\mathrm{N}_{2}$ to $\mathrm{NH}_{3}$ conversion. The overall reaction for $\mathrm{N}_{2}$ reduction to $\mathrm{NH}_{3}$ is highly exothermic due to the combination of strong protonic acid and reductant adopted in the calculations, which is the same as those in Nishibayashi's synthesis paper $[34,35]$. On the other hand, with the growth of the number of Mo centers in the model complexes, a drastic dimensional effect was found on the reaction energetics for the respective protonation and reduction processes. As shown in Fig. 1, the reactions catalyzed by the monometallic complex $[\mathrm{Mo}]_{1}$ exhibit a zigzag feature on the energetic profile, leading to a set of reaction hurdles basically corresponding to the protonation processes. With the increase of the 
number of metal centers in the polynuclear model complexes, those energetic hurdles were gradually removed. At $[\mathrm{Mo}]_{3}$ or longer chains, the energies of the reaction system on the whole evolved in a monotonically descending manner upon a sequential additions of the acid [LutH $]^{+}$ and the reductants $\operatorname{Co}\left(\mathrm{Cp}^{*}\right)_{2}$, and the reactions are generally exothermic or neutral for the formation of each intermediates. With respect to the reaction thermodynamics, the catalyzed reactions from $\mathrm{N}_{2}$ to $\mathrm{NH}_{3}$ may proceed smoothly when polynuclear [Mo] 3 or lager complexes are used as catalysts.

As described in Scheme 2, in homologous catalytic systems, $\mathrm{N}_{2}$ undergoes a long journey to the $\mathrm{NH}_{3}$ transformation, and many elementary processes are involved in the catalytic cycle. Although the overall reaction from $\mathrm{N}_{2}$ to $\mathrm{NH}_{3}$ conversion is highly exothermic, barriers may exist to inhibit the occurrence of reactions in the catalytic cycle. For the given combination of proton and electron sources, an ideal catalyst would direct the reactions proceeding along the imaginary straight line (no barrier) in Fig. 1, which starts from $\mathrm{N}_{2}$ and ends at two $\mathrm{NH}_{3}$. With the polynuclear complexes of $[\mathrm{Mo}]_{3}$ or longer chains, it is noteworthy that the reaction energetic profiles gradually approach the imaginary line, albeit smaller barriers remain in some reaction steps.

Now we take a closer inspection of the catalytic performance of the Mo complexes by varying the number of metal centers. For $[\mathrm{Mo}]_{1}$ as shown in Fig. 1, protonation of the nitrogenous ligands coordinated to Mo centers are thermodynamically unfavorable, which is in contrast to the exothermic reductions processes. The most difficult protonation processes correspond to the formation of diazenido $\left(\mathbf{M o N N H}{ }^{+}, \Delta \mathrm{E}=+29.5 \mathrm{kcal} \mathrm{mol}^{-1}\right)$, hydrazido $\left(\mathbf{M o N N H}_{2}{ }^{2+}, \Delta \mathrm{E}=+15.03\right.$ $\left.\mathrm{kcal} \mathrm{mol}^{-1}\right)$ and imide $\left(\mathbf{M o N H}^{2+}, \Delta \mathrm{E}=+24.97 \mathrm{kcal} \mathrm{mol}^{-1}\right)$ moieties, which is in accordance with 
the previously reported calculations.[34, 35] For the bimetallic complex $[\mathrm{Mo}]_{2}$, those protonation processes become easier, whereas great hurdles still remain for those protonated intermediates formation $\left(\mathbf{M o N N H}^{+}, \Delta \mathrm{E}=+15.75 \mathrm{kcal} \mathrm{mol}^{-1}, \mathbf{M o N N H}_{2}{ }^{2+}, \Delta \mathrm{E}=+3.39 \mathrm{kcal} \mathrm{mol}^{-1}, \mathbf{M o N H}^{2+}, \Delta \mathrm{E}\right.$ $\left.=+14.98 \mathrm{kcal} \mathrm{mol}^{-1}\right)$. Further increase of the polynuclear complexes as for $[\mathrm{Mo}]_{3}$, the protonation barriers were basically erased $\left(\mathbf{M o N N H}^{+}, \Delta \mathrm{E}=+3.78 \mathrm{kcal} \mathrm{mol}^{-1}, \mathbf{M o N N H}_{2}{ }^{2+}, \Delta \mathrm{E}=-0.84 \mathrm{kcal}\right.$ $\left.\mathrm{mol}^{-1}, \mathrm{MoNH}^{2+}, \Delta \mathrm{E}=+3.51 \mathrm{kcal} \mathrm{mol}^{-1}\right)$. With even larger model complexes for instance $[\mathrm{Mo}]_{4}$ and $[\mathrm{Mo}]_{5}$, the reaction energetic profiles are nearly the same as that for $[\mathrm{Mo}]_{3}$ as shown in Fig. 1. In this respect, the dimensional get saturated at $[\mathrm{Mo}]_{3}$ for the set of polynuclear Mo-complexes structurally analogues to the Nishibayashi bimetallic compounds.

The Mo atoms are in the oxidation state of zero for the $\mathrm{N}_{2}$ bridged model complexes in this study as well as for those in the Nishibayashi complex. In this regard, this class of polynuclear Mo complexes resembles the Chatt systems, for which $\operatorname{Mo}(0)$ is involved. It has been suggested that in Chatt reaction systems, the most difficult reaction step is the initial protonation of the $\mathrm{N}_{2}$ ligated to Mo center [55-57].This is in line with the strongly endothermic protonation of the $\mathrm{N}_{2}$ ligand in the monometallic Mo complex in this study. In monometallic complexes, the protonation resistance of the $\mathrm{N}_{2}$ ligand can also be seen in the catalytic $\mathrm{N}_{2}$ reduction by the Mo(III) complex in Schrock systems $[56,58]$. In the Schrock catalytic systems, theoretical calculations suggested that rather than direct protonation, the first proton addition on the terminal $\mathrm{N}_{2}$ ligand is accomplished by a proton-catalyzed reductive protonation with the involvement of a triamidoamine ligand. The above evidence strongly suggests that the first protonation step of $\mathrm{N}_{2}$ ligand is a crucial step in the catalytic cycle of $\mathrm{N}_{2}$ to $\mathrm{NH}_{3}$ conversion [59]. In this context, the decrease or completely removal of the protonation hurdle of the terminal $\mathrm{N}_{2}$ ligand is nontrivial 
to enhance the $\mathrm{N}_{2}$ to $\mathrm{NH}_{3}$ transformation in homogenous catalytic systems. According to the calculations with the model Mo complexes as shown in Fig. 1, the protonation of the terminal $\mathrm{N}_{2}$ ligand is almost thermodynamically neutral, when $[\mathrm{Mo}]_{3}$ or lager polynuclear complexes are used as possible catalysts.

The reason behind the dimensional effect on the protonation of $\mathrm{N}_{2}$ can be seen from a qualitative natural population analysis (NPA) [60]. The atomic charges in the polynuclear complexes are partitioned into two parts as illustrated in Scheme 3, where the first portion (Part 1) includes the corresponding ligands and a Mo center involved in protonation (see Scheme S3 for details). Table 1 (the left part) tabulates the atomic charge changes upon the first protonation of $\mathrm{N}_{2}$ leading to $\mathrm{MoNNH}^{+}$for the set of model complexes, and the respective energetics are also listed. One notes that with the increase of the number of Mo centers, the positive charges introduced by the first proton addition to the complexes become more delocalized along the polynuclear chains. For $[\mathrm{Mo}]_{1}$, the positive charge of +1 is undoubtedly accumulated on Part 1 , while for $[\mathrm{Mo}]_{2}$ significant positive charges are delocalized onto Part 2. In $[\mathrm{Mo}]_{3}$ or longer chains, the positive charges on Part 1 become even smaller, while those on Part 2 gradually grow. A joint inspection of NPA analysis and the energetics indicates that they are closely related to each other as shown in Table 1. With the increase of polynuclear chains, the first protonation of the $\mathrm{N}_{2}$ ligand becomes easier due to the more delocalized charge distribution. 
Scheme 3. Structure Partition of the Polynuclear Complexes for Atomic Charge Counting as Listed in Table 1.
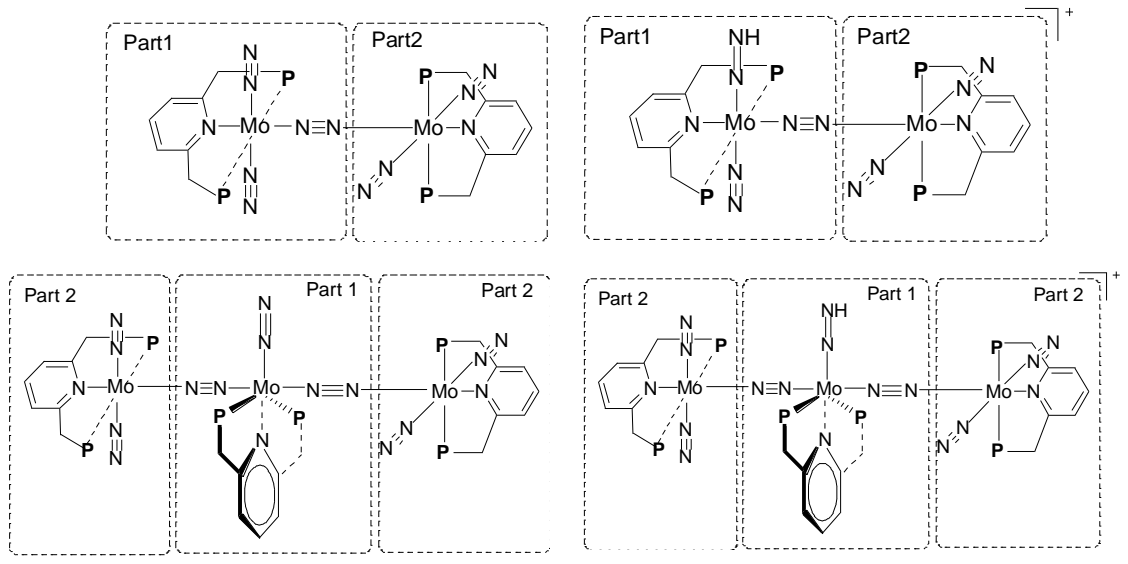

Table 1. Changes of the NPA Charges $(\Delta \mathrm{Q}$ in $|\mathrm{e}|)$ and the Related Protonation Energies $(\Delta \mathrm{E}$ in kcal $\mathrm{mol}^{-1}$ ) Corresponding to the First Two Consecutive Protonation in the $\mathrm{N}_{2}$-bridged Model Complexes.

\begin{tabular}{ccccc}
\hline & \multicolumn{2}{c}{ MoNN $\rightarrow$ MoNNH $^{+}$} & \multicolumn{2}{c}{ MoNNH $^{+} \rightarrow$ MoNNH $_{2}{ }^{2+}$} \\
& $\left.\Delta \mathrm{Q}\right|_{\text {Part1/Part2 }}{ }^{\mathrm{a}}$ & $\Delta \mathrm{E}^{\mathrm{b}}$ & $\left.\Delta \mathrm{Q}\right|_{\text {Part1//Part2 }}{ }^{\mathrm{a}}$ & $\Delta \mathrm{E}^{\mathrm{b}}$ \\
{$[\mathrm{Mo}]_{1}$} & $1.000 / 0$ & 29.50 & $2.000 / 0$ & 15.03 \\
{$[\mathrm{Mo}]_{2}$} & $0.700 / 0.300$ & 15.75 & $1.409 / 0.591$ & 3.39 \\
{$[\mathrm{Mo}]_{3}$} & $0.535 / 0.465$ & 3.78 & $1.164 / 0.836$ & -0.84 \\
{$[\mathrm{Mo}]_{4}$} & $0.490 / 0.510$ & 3.70 & $1.073 / 0.927$ & -1.75 \\
{$[\mathrm{Mo}]_{5}$} & $0.450 / 0.550$ & 3.84 & $1.003 / 0.997$ & -2.64
\end{tabular}

${ }^{\mathrm{a}} \mathrm{See}$ Scheme 3 for the structure partition for Part 1 and Part 2. Part 1 is the segment consisting of a Mo center and the related ligands directly involved in protonation.

${ }^{\mathrm{b}}$ The energy change upon protonation.

Another remarkable observation from Fig. 1 is the strong size effect of the Mo complexes on the second protonation giving the formation of $\mathbf{M o N N H}_{2}{ }^{2+}$. According to the calculations for multimetallic complexes, the further protonation of $\mathrm{MoNNH}^{+}$is thermodynamically favored over its reduction by $\operatorname{CoCp}_{2}{ }_{2}$ (see Scheme S2 in the SI). For the monometallic complex $[\mathrm{Mo}]_{1}$, the second protonation is highly endothermic $\left(\Delta \mathrm{E}=+15.03 \mathrm{kcal} \mathrm{mol}^{-1}\right)$, which is not surprising due to the two positive charges confined in a limited space for monometallic $[\mathrm{Mo}]_{1}$. On the other 
hand, for $[\mathrm{Mo}]_{3}$ or longer polynuclear chains, facile protonation of $\mathbf{M o N N H}^{+}$is possible leading to the formation of $\mathbf{M o N N H}_{2}{ }^{2+}\left(\Delta \mathrm{E}=-0.84 \mathrm{kcal} \mathrm{mol}^{-1}\right.$, for $\left.[\mathbf{M o}]_{3}\right)$. The reason for the size effect on the second protonation can be seen in a similar manner of atomic charge analysis. From Table 1 (the right half), one notes that the longer polynuclear chains favor to delocalize the two positive charges onto more metal centers thereby leading to facile protonation process of $\mathbf{M o N N H}^{+} \rightarrow$ $\mathrm{MoNNH}_{2}{ }^{2+}$.

For rest of the reaction steps in the catalytic cycle of Scheme 2, the protonation processes benefits from the increased polynuclear chain lengths, and at the same time the reduction reactions are basically kept exothermic. The ligand exchange of $\mathrm{NH}_{3}$ by $\mathrm{N}_{2}$ has been suggested to be the limiting step in the Schrock catalytic cycle $[52,61,62]$. The difficulty of ligand exchange has been attributed to both thermodynamic and kinetic factors. The bulky ligands used in Schrock complexes kinetically inhibit the release of $\mathrm{NH}_{3}$, and at the same time the relatively strong binding between $\mathrm{NH}_{3}$ and Mo centers also contributes. From Fig. 1, it is noteworthy that the energy change for a $\mathrm{NH}_{3}$ release $(\mathbf{1 1} \rightarrow \mathbf{1 2})$ decreases from $+23.95 \mathrm{kcal} \mathrm{mol}^{-1}$ to $+17.77 \mathrm{kcal}$ $\mathrm{mol}^{-1}$ corresponding to the cases of $[\mathrm{Mo}]_{1}$ and $[\mathrm{Mo}]_{5}$, respectively. Therefore, the size effect is also thermodynamically beneficial for the ligand exchange reactions.

\section{Replacement of the bridging $\mathrm{N}_{2}$ ligand with $[: \mathrm{C} \equiv \mathrm{C}:]^{2-}$ carbide}

Given the strong size effect on catalytic activities as evidenced by the polynuclear models featuring $\mathrm{N}_{2}$-bridged ligands, we are intrigued if the catalytic performance would be improved when different bridging ligands are used in a polynuclear complex variant. The $[: \mathrm{C} \equiv \mathrm{C}:]^{2-}$ carbide was chosen as it has two possible benefits. Firstly, the carbide bridging ligand is expected to provide a better electronic communication pathway between the Mo centers. Besides, the stronger 
coordination bonding between the carbide and Mo atoms likely afford more stable polynuclear complexes as effective catalysts in homogenous solution systems. The structures of $\mathrm{C}_{2}$-bridged complexes are similar to the $\mathrm{N}_{2}$-bridged ones except for the bridging ligands as illustrated in Scheme 1. Fig. 2 presents the calculated energetic profiles of $\mathrm{N}_{2}$ to $\mathrm{NH}_{3}$ reduction catalyzed by the model complexes with multi-Mo centers bridged by $[: \mathrm{C} \equiv \mathrm{C}:]^{2-}$ ligands.

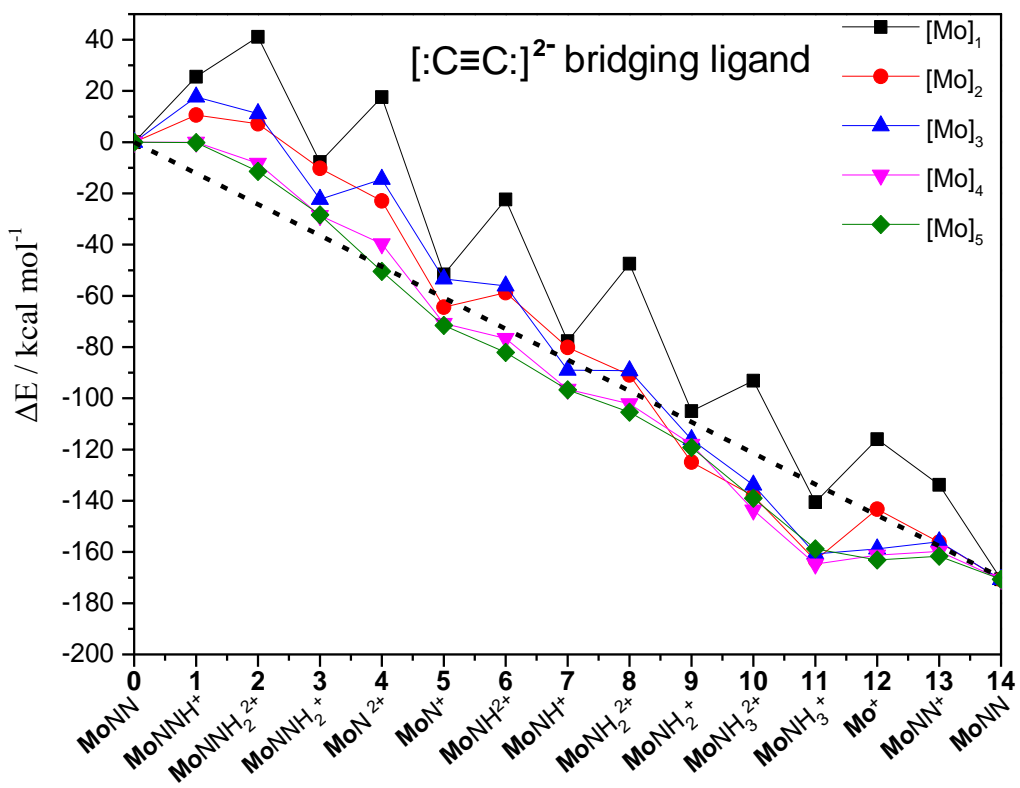

Fig. 2 The energetic profiles for $\mathrm{N}_{2}$ to $\mathrm{NH}_{3}$ transformation catalyzed by the model complexes containing different number of Mo atoms bridged by $[: \mathrm{C} \equiv \mathrm{C}:]^{2-}$ carbide ligands. An imaginary dash line was added connecting $\mathrm{N}_{2}$ and $\mathrm{NH}_{3}$ on the profile, and the energy difference between them is determined by the proton and electron sources used.

The carbide bridged complexes exhibit similar thermodynamic characteristics as those of $\mathrm{N}_{2}$-bridged systems. Nevertheless, according to the energetic profiles in Fig. 2, a more remarkable size effect on the catalytic performance was observed for the carbide-based model complexes. One notes that for $[\mathrm{Mo}]_{4}$ or longer chains, the reaction energetic profiles approach that for an ideal catalyst as represented by an imaginary straight line starting from $\mathrm{N}_{2}$ and monotonically descending to $\mathrm{NH}_{3}$ for the given combination of proton and electron sources used 
in this study. As shown in Fig. 2, for the mononuclear complex $[\mathrm{Mo}]_{1}$, the reaction energetic profile takes a zigzag pattern with the reaction barriers corresponding to the very endothermic protonation processes. When $[\mathrm{Mo}]_{2}$ complex was used, the protonation energies were considerably reduced, albeit a relatively high obstacle remained for the first proton addition to $\mathrm{N}_{2}$ $\left(\mathrm{MoNN} \rightarrow \mathrm{MoNNH}^{+}\right.$). The reduced protonation hurdle is in accordance with the more delocalized charges in $[\mathrm{Mo}]_{2}$ as shown in Table 2, where the changes of atomic charges are listed corresponding to the first two protonation processes. Interestingly, further increasing the polynuclear chain to a length of $[\mathrm{Mo}]_{3}$, no obvious change on the reaction energetic profile was observed in comparison with $[\mathrm{Mo}]_{2}$. This is possibly related to two competitive factors, one for the different oxidation states of the Mo atoms and the other for the polynuclear chain length. For $[\mathrm{Mo}]_{1}$ and $[\mathrm{Mo}]_{2}$, the metal atoms are in the oxidation state of +1 , while for $[\mathrm{Mo}]_{3}$, both $\mathrm{Mo}(\mathrm{I})$ and $\mathrm{Mo}(\mathrm{II})$ can be found corresponding to the Mo atoms at the ends and in the middle of the chain, respectively. One notes that the increased chain length from $[\mathrm{Mo}]_{2}$ to $[\mathrm{Mo}]_{3}$ favors the protonation processes, on the other hand, the higher oxidation state of $\mathrm{Mo}(\mathrm{II})$ is likely to inhibit protonation of $\mathrm{N}_{2}$ in $[\mathrm{Mo}]_{3}$. Further increasing the chains to $[\mathrm{Mo}]_{4}$ and $[\mathrm{Mo}]_{5}$, as shown in Fig. 2, the thermodynamic hurdles were removed for the set of protonation processes, and the reactions are likely to proceed in monotonically descending fashion on the energetic profiles for the sequenced protonation and reduction processes in the catalytic cycle. The reaction paths for $[\mathrm{Mo}]_{4}$ and $[\mathrm{Mo}]_{5}$ on the energetic profiles approach very closely to that for an ideal catalyst as represented by an imaginary straight line (no barrier) on the energy profile as shown in Fig. 2 . Among the set of model complexes, $[\mathrm{Mo}]_{3},[\mathrm{Mo}]_{4}$ and $[\mathrm{Mo}]_{5}$ have a similar feature for the oxidation states of the Mo atoms, and hence the size of the polynuclear chains should be the main 
factor affecting catalytic activities. As shown in Table 2, upon the first two proton additions, the positive charges are mainly delocalized on Part 2 (see Scheme S3 for structures) in $[\mathrm{Mo}]_{4}$ and $[\mathrm{Mo}]_{5}$ complexes, while significant charge increase was found in Part 1 for $[\mathrm{Mo}]_{3}$. That explains the more favorable catalytic processes for $[\mathrm{Mo}]_{4}$ and $[\mathrm{Mo}]_{5}$.

Table 2. Changes of the NPA Charges $(\Delta \mathrm{Q}$ in $|\mathrm{e}|)$ and the Related Protonation Energies $(\Delta \mathrm{E}$ kcal $\mathrm{mol}^{-1}$ ) Corresponding to the First Two Consecutive Proton Additions in the $\mathrm{C}_{2}$-bridged Model Complexes.

\begin{tabular}{ccccc} 
& \multicolumn{2}{c}{$\mathrm{MoNN} \rightarrow \mathrm{MoNNH}^{+}$} & \multicolumn{2}{c}{$\mathbf{M o N N H}^{+} \rightarrow \mathrm{MoNNH}_{2}{ }^{2+}$} \\
& $\left.\Delta \mathrm{Q}\right|_{\text {Part1/Part2 }}{ }^{\mathrm{a}}$ & $\Delta \mathrm{E}^{\mathrm{b}}$ & $\left.\Delta \mathrm{Q}\right|_{\text {Part1/Part2 }^{\mathrm{a}}}$ & $\Delta \mathrm{E}^{\mathrm{b}}$ \\
{$[\mathrm{Mo}]_{1}$} & $1.000 / 0$ & 25.54 & $2.000 / 0$ & 15.62 \\
{$[\mathrm{Mo}]_{2}$} & $0.689 / 0.311$ & 10.57 & $1.422 / 0.578$ & -3.37 \\
{$[\mathrm{Mo}]_{3}$} & $0.340 / 0.660$ & 17.64 & $1.075 / 0.925$ & -6.46 \\
{$[\mathrm{Mo}]_{4}$} & $-0.078 / 1.078$ & 0.01 & $0.647 / 1.355$ & -8.28 \\
{$[\mathrm{Mo}]_{5}$} & $-0.074 / 1.074$ & -0.16 & $0.477 / 1.523$ & -11.26 \\
\hline
\end{tabular}

${ }^{\text {a }}$ See Scheme S3 for the structure partition for Part 1 and Part 2. Part 1 is the segment consisting of a Mo center and the related ligands directly involved in protonation.

${ }^{\mathrm{b}}$ The energy change upon protonation.

Another significant observation from Fig. 2 is the facile ligand exchange from $\mathrm{NH}_{3}$ to $\mathrm{N}_{2}$, when the carbide-based $[\mathrm{Mo}]_{3}$ or larger complexes were used. In $[\mathrm{Mo}]_{3},[\mathrm{Mo}]_{4}$ and $[\mathrm{Mo}]_{5}$ systems, the release of a $\mathrm{NH}_{3}$ molecule $\left(\mathrm{MoNH}_{3}{ }^{+} \rightarrow \mathbf{M o}^{+}\right)$is nearly barrierless as seen in Fig. 2, which is in sharp contrast to the endothermic feature for that in $[\mathrm{Mo}]_{1}$ and $[\mathrm{Mo}]_{2}$ systems. The spontaneous $\mathrm{NH}_{3}$ extrusion in $[\mathrm{Mo}]_{3}$ system might be related to the change of the metal oxidation state from $\operatorname{Mo}(\mathrm{IV}) \mathrm{NH}_{3}{ }^{2+}$ to $\mathbf{M o}(\mathrm{III})^{+}$. The Mo atoms in $\mathbf{M o}(\mathrm{IV}) \mathrm{NH}_{3}{ }^{2+}$ moiety was originally in a six coordinated environment. One-electron reduction and a concurrent $\mathrm{NH}_{3}$ extrusion led to $\mathrm{Mo}(\mathrm{III})^{+}$, which turned to be five-coordinated. This is actually in line with the Schrock complex, where the Mo(III) atom is also five-coordinated including a triamidoamine ligand and a $\mathrm{N}_{2}$ ligand[23]. 


\section{Comparison of the two kinds of bridging ligands $\left(\mathrm{N} \equiv \mathrm{N}\right.$ vs $\left.[: \mathrm{C} \equiv \mathrm{C}:]^{2-}\right)$}

As mentioned before, the size effects approach saturated at polynuclear [Mo] $]_{4}$ both for the $\mathrm{N}_{2}$ and carbide bridged systems. For this reason, $[\mathrm{Mo}]_{4}-\mathrm{N}_{2}$ and $[\mathrm{Mo}]_{4}-\mathrm{C}_{2}$ were used to comparatively explore the ligand effect on the catalytic activities, where $[\mathrm{Mo}]_{4}-\mathrm{N}_{2}$ and $[\mathrm{Mo}]_{4}-\mathrm{C}_{2}$ refer to the polynuclear models containing four Mo centers bridged by $\mathrm{N}_{2}$ and carbide ligands, respectively. As shown in Fig. 3, in the [Mo] $]_{4}-\mathrm{N}_{2}$ catalyzed system, a few thermodynamic hurdles remain for the protonation processes, such as $\mathrm{MoNN} \rightarrow \mathrm{MoNNH}^{+}$and $\mathrm{MoN}^{+} \rightarrow \mathrm{MoNH}^{2+}$. In contrast, those reaction hurdles disappeared when $[\mathrm{Mo}]_{4}-\mathrm{C}_{2}$ was used. By comparing the atomic charge distributions corresponding to the first two proton addition to $\mathrm{N}_{2}$ ligand, it was found that the introduced positive charges are more delocalized in $[\mathrm{Mo}]_{4}-\mathrm{C}_{2}$ (Table 2) than in $[\mathrm{Mo}]_{4}-\mathrm{N}_{2}$ (Table 1) systems. This suggests that the $[: \mathrm{C} \equiv \mathrm{C}:]^{2-}$ carbide ligand enables more effective electronic dispersion and thereby more favorable catalytic activities than the $\mathrm{N}_{2}$ bridging ligand. Compared with $[\mathrm{Mo}]_{4}-\mathrm{N}_{2}$, another distinguished feature of $[\mathrm{Mo}]_{4}-\mathrm{C}_{2}$ is the facile $\mathrm{NH}_{3}$ release corresponding to $\mathrm{MoNH}_{3}^{+} \rightarrow \mathrm{Mo}^{+}$, which was attributed to the change of oxidation states and coordination preferences of $\mathrm{Mo}(\mathrm{III})^{+}$as mentioned before. 


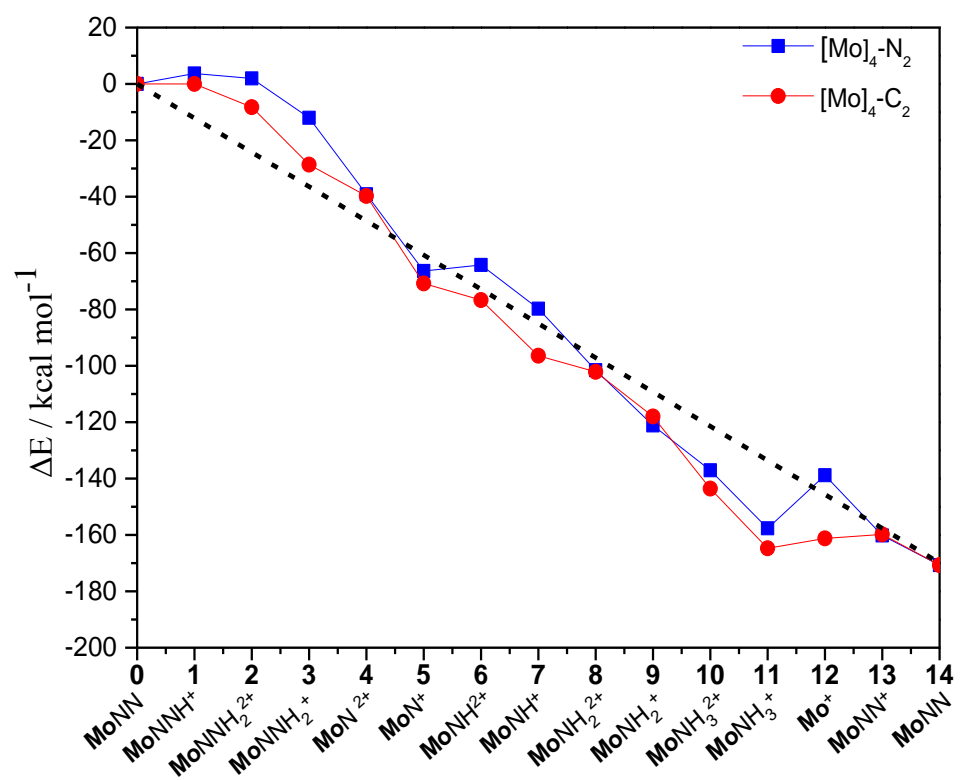

Fig. 3 The energetic profiles of $\mathrm{N}_{2}$ to $\mathrm{NH}_{3}$ conversion catalyzed by $[\mathrm{Mo}]_{4}-\mathrm{N}_{2}$ and $[\mathrm{Mo}]_{4}-\mathrm{C}_{2}$ in the presence of $[\mathrm{LutH}]^{+}$and $\mathrm{Co}\left(\mathrm{Cp}^{*}\right)_{2}$

For a given pair of proton and electron sources, such as $[\mathrm{LutH}]^{+}$and $\mathrm{Co}\left(\mathrm{Cp}^{*}\right)_{2}$ employed for calculations in this study, the overall reaction energy for the complete conversion of $\mathrm{N}_{2}$ to $\mathrm{NH}_{3}$ is determined [63], which is irrespective of the catalyst used. On the other hand, for different catalysts used, the catalytic pathway may exhibit diverse patterns on the energy profiles. From the thermodynamic perspective, high catalytic efficiency would be obtained if an ideal catalyst could be found, which directed the reactions proceeding along the imaginary line in a monotonically descending fashion from $\mathrm{N}_{2}$ to $\mathrm{NH}_{3}$ as shown in Fig. 3 (the dash line). Compared with $[\mathrm{Mo}]_{4}-\mathrm{N}_{2}$, the respective intermediates in the $[\mathrm{Mo}]_{4}-\mathrm{C}_{2}$ catalyzed systems are located more closely to the ideal case represented by the imaginary straight line, which indicates that $[\mathrm{Mo}]_{4}-\mathrm{C}_{2}$ could have a better catalytic performance than $[\mathrm{Mo}]_{4}-\mathrm{N}_{2}$.

\section{Conclusions}


As an extending study of the catalytic activities of the Nishibayashi-type Mo dinitrogen complex, we computationally explored how the number of metal centers bridged by different types of ligands affects the catalytic $\mathrm{N}_{2}$ reduction to $\mathrm{NH}_{3}$ by using a set of polynuclear model complexes. As a chain-like extension of the Nishibayashi's bimetallic complex featuring a $\mathrm{N}_{2}$-bridged ligand, we found that the polynuclear complexes containing three or more Mo centers are likely to drastically enhance the catalytic performance of the Mo-based catalysts by comparing to both the monometallic and bimetallic complexes. The dimensional effect gets saturated at $[\mathrm{Mo}]_{3}-\mathrm{N}_{2}$, and further increase of the number of metal centers does not significantly improve the catalytic efficiency any more. The increase of the polynuclear chain size was also found to thermodynamically favor the $\mathrm{NH}_{3}$ release from the metal center, which has been thought to be a challenging step in the Mo-based catalytic systems for $\mathrm{N}_{2}$ to $\mathrm{NH}_{3}$ conversion. When the bridging $\mathrm{N}_{2}$ ligands were replaced with carbides $\left.[: \mathrm{C} \equiv \mathrm{C}:]^{2-}\right]$ in the polynuclear chains, a remarkable improvement was observed in terms of the thermodynamics corresponding to the formation of the reaction intermediates. For $[\mathrm{Mo}]_{4}-\mathrm{C}_{2}$ or longer chains, no obvious thermodynamic hurdle was found along the catalytic pathway from $\mathrm{N}_{2}$ to $\mathrm{NH}_{3}$. The enhanced catalytic performance for longer polynuclear chains was ascribed to the more delocalized charge distribution introduced by the proton or electron addition processes. For the carbide bridged polynuclear models, the electronic communication is more effective than that for $\mathrm{N}_{2}$-bridged systems, as reflected by the more delocalized charges upon protonation. In the carbide bridged polynuclear models, facile $\mathrm{NH}_{3}$ release from the metal center was observed upon the reduction of $\mathrm{Mo}(\mathrm{IV}) \mathrm{NH}_{3}{ }^{2+}$ to $\mathrm{Mo}(\mathrm{III})^{+}$, which was associated with the change of oxidation states of the metal centers and their coordination preferences. The high catalytic efficiency predicted for $[\mathrm{Mo}]_{4}-\mathrm{C}_{2}$ or its longer 
analogous indicates that a highly efficient catalytic model system might be designed by extending the polynuclear chains to a proper size and by employing an effective bridging ligand for charge dispersion.

\section{Acknowledgements}

This research was supported by the National Science Foundation of China (Grant No. 21443012) and the Faculty Startup Grant of Sichuan University. We thank the National Supercomputing Center in Shenzhen for providing the computational resources.

\section{Appendix A. Supplementary data}

Supplementary data related to this article can be found at http:// dx.doi.org/10.1016/j.jorganchem.xxxx.xx.xxx.

\section{References}

[1] A. Shilov, Catalytic reduction of molecular nitrogen in solutions, Russ. Chem. Bull. 52 (2003) 2555-2562.

[2] C.-G. Zhan, J.A. Nichols, D.A. Dixon, Ionization potential, electron affinity, electronegativity, hardness, and electron excitation energy: molecular properties from density functional theory orbital energies, J. Phys. Chem. A 107 (2003) 4184-4195.

[3] V. Smil, Enriching the earth: Fritz Haber, Carl Bosch, and the Transformation of World Food Production, MIT Press: Boston 2004.

[4] B.K. Burgess, D.J. Lowe, Mechanism of molybdenum nitrogenase, Chem. Rev. 96 (1996) 2983-3012.

[5] J.B. Howard, D.C. Rees, Structural basis of biological nitrogen fixation, Chem. Rev. 96 (1996) 2965-2982.

[6] B.M. Hoffman, D. Lukoyanov, Z.Y. Yang, D.R. Dean, L.C. Seefeldt, Mechanism of nitrogen fixation by nitrogenase: the next stage, Chem. Rev. 114 (2014) 4041-4062.

[7] T. Shima, S. Hu, G. Luo, X. Kang, Y. Luo, Z. Hou, Dinitrogen cleavage and hydrogenation by a trinuclear titanium polyhydride complex, Science 340 (2013) 1549-1552.

[8] J.L. Crossland, D.R. Tyler, Iron-dinitrogen coordination chemistry: Dinitrogen activation and reactivity, Coord. Chem. Rev. 254 (2010) 1883-1894.

[9] M.D. Fryzuk, S.A. Johnson, The continuing story of dinitrogen activation, Coord. Chem. Rev. 200 (2000) 379-409.

[10] R.B. Siedschlag, V. Bernales, K.D. Vogiatzis, N. Planas, L.J. Clouston, E. Bill, L. Gagliardi, C.C. Lu, Catalytic Silylation of Dinitrogen with a Dicobalt Complex, J. Am. Chem. Soc. 137 (2015) 4638-4641. 
[11] Y. Li, Y. Li, B. Wang, Y. Luo, D. Yang, P. Tong, J. Zhao, L. Luo, Y. Zhou, S. Chen, Ammonia formation by a thiolate-bridged diiron amide complex as a nitrogenase mimic, Nat. Chem. 5 (2013) 320-326.

[12] C.E. Laplaza, C.C. Cummins, Dinitrogen Cleavage by a Three-Coordinate Molybdenum(III) Complex, Science 268 (1995) 861-863.

[13] K. Komori, H. Oshita, Y. Mizobe, M. Hidai, Catalytic conversion of molecular nitrogen into silylamines using molybdenum and tungsten dinitrogen complexes, J. Am. Chem. Soc. 111 (1989) 1939-1940.

[14] M.D. Fryzuk, Side-on End-on Bound Dinitrogen: An Activated Bonding Mode That Facilitates Functionalizing Molecular Nitrogen, Acc. Chem. Res. 42 (2009) 127-133.

[15] C. Sivasankar, S. Baskaran, M. Tamizmani, K. Ramakrishna, Lessons learned and lessons to be learned for developing homogeneous transition metal complexes catalyzed reduction of $\mathrm{N} 2$ to ammonia, J. Organomet. Chem. 752 (2014) 44-58.

[16] J. Chatt, A.J. Pearman, R.L. Richards, The reduction of mono-coordinated molecular nitrogen to ammonia in a protic environment, Nature 253 (1975) 39-40.

[17] J. Chatt, J.R. Dilworth, R.L. Richards, Recent advances in the chemistry of nitrogen fixation, Chem. Rev. 78 (1978) 589-625.

[18] Y. Nishibayashi, Recent progress in transition-metal-catalyzed reduction of molecular dinitrogen under ambient reaction conditions, Inorg. Chem. 54 (2015) 9234-9247.

[19] B. Askevold, J.T. Nieto, S. Tussupbayev, M. Diefenbach, E. Herdtweck, M.C. Holthausen, S. Schneider, Ammonia formation by metal-ligand cooperative hydrogenolysis of a nitrido ligand, Nat. Chem. 3 (2011) 532-537.

[20] M.M. Rodriguez, E. Bill, W.W. Brennessel, P.L. Holland, N2 reduction and hydrogenation to ammonia by a molecular iron-potassium complex, Science 334 (2011) 780-783.

[21] J.A. Pool, E. Lobkovsky, P.J. Chirik, Hydrogenation and cleavage of dinitrogen to ammonia with a zirconium complex, Nature 427 (2004) 527-530.

[22] M.D. Fryzuk, J.B. Love, S.J. Rettig, V.G. Young, Transformation of coordinated dinitrogen by reaction with dihydrogen and primary silanes, Science 275 (1997) 1445-1447.

[23] D.V. Yandulov, R.R. Schrock, Catalytic reduction of dinitrogen to ammonia at a single molybdenum center, Science 301 (2003) 76-78.

[24] K. Arashiba, Y. Miyake, Y. Nishibayashi, A molybdenum complex bearing PNP-type pincer ligands leads to the catalytic reduction of dinitrogen into ammonia, Nat. Chem. 3 (2011) 120-125. [25] J.S. Anderson, J. Rittle, J.C. Peters, Catalytic conversion of nitrogen to ammonia by an iron model complex, Nature 501 (2013) 84-87.

[26] G. Ung, J.C. Peters, Low-temperature N2 binding to two-coordinate L2Fe(0) enables reductive trapping of L2FeN2(-) and NH3 generation, Angew. Chem. Int. Ed. 54 (2015) 532-535. [27] T.A. Bazhenova, A.E. Shilov, Nitrogen fixation in solution, Coord. Chem. Rev. 144 (1995) 69-145.

[28] K. Shiina, Reductive silylation of molecular nitrogen via fixation to tris(trialkylsilyl)amine, J. Am. Chem. Soc. 94 (2002) 9266-9267.

[29] H. Tanaka, A. Sasada, T. Kouno, M. Yuki, Y. Miyake, H. Nakanishi, Y. Nishibayashi, K. Yoshizawa, Molybdenum-catalyzed transformation of molecular dinitrogen into silylamine: experimental and DFT study on the remarkable role of ferrocenyldiphosphine ligands, J. Am. Chem. Soc. 133 (2011) 3498-3506. 
[30] M. Mori, Activation of nitrogen for organic synthesis, J. Org. Chem. 689 (2004) 4210-4227. [31] M. Yuki, H. Tanaka, K. Sasaki, Y. Miyake, K. Yoshizawa, Y. Nishibayashi, Iron-catalysed transformation of molecular dinitrogen into silylamine under ambient conditions, Nat. Commun. 3 (2012) 1254.

[32] J. Rittle, C.C. McCrory, J.C. Peters, A 106-Fold Enhancement in N2-Binding Affinity of an Fe2 $(\mu-\mathrm{H}) 2$ Core upon Reduction to a Mixed-Valence FeIIFeI State, J. Am. Chem. Soc. 136 (2014) 13853-13862.

[33] S.E. Creutz, J.C. Peters, Catalytic Reduction of N2 to NH3 by an Fe-N2 Complex Featuring a C-Atom Anchor, J. Am. Chem. Soc. 136 (2014) 1105-1115.

[34] Y.H. Tian, A.W. Pierpont, E.R. Batista, How does Nishibayashi's molybdenum complex catalyze dinitrogen reduction to ammonia?, Inorg. Chem. 53 (2014) 4177-4183.

[35] H. Tanaka, K. Arashiba, S. Kuriyama, A. Sasada, K. Nakajima, K. Yoshizawa, Y.

Nishibayashi, Unique behaviour of dinitrogen-bridged dimolybdenum complexes bearing pincer ligand towards catalytic formation of ammonia, Nat. Commun. 5 (2014) 3737.

[36] S. Kuriyama, K. Arashiba, K. Nakajima, H. Tanaka, N. Kamaru, K. Yoshizawa, Y.

Nishibayashi, Catalytic formation of ammonia from molecular dinitrogen by use of dinitrogen-bridged dimolybdenum-dinitrogen complexes bearing PNP-pincer ligands: remarkable effect of substituent at PNP-pincer ligand, J. Am. Chem. Soc. 136 (2014) 9719-9731.

[37] J. Chatt, G.A. Heath, R.L. Richards, Diazene-N-(di-imide) and hydrazido-(2-)

$\mathrm{N}$-(aminoimido) complexes: the addition of acids to dinitrogen complexes, J. Chem. Soc., Dalton Trans. (1974) 2074-2082.

[38] M. Vol'Pin, V. Shur, Nitrogen fixation by transition metal complexes, Nature 209 (1966) 1023.

[39] A.D. Becke, Density - functional thermochemistry. III. The role of exact exchange, J. Chem. Phys. 98 (1993) 5648-5652.

[40] P. Stephens, F. Devlin, C. Chabalowski, M.J. Frisch, Ab initio calculation of vibrational absorption and circular dichroism spectra using density functional force fields, J. Phys. Chem. 98 (1994) 11623-11627.

[41] M. Frisch, G. Trucks, H.B. Schlegel, G. Scuseria, M. Robb, M, J. Cheeseman, G, Scalmani, V, Barone, B. Mennucci, G. Petersson, H. Nakatsuji, M. Caricato, X. Li, H. Hratchian, A. Izmaylov, J. Bloino, G. Zheng, J. Sonnenberg, M. Hada, M. Ehara, K. Toyota, R. Fukuda, J. Hasegawa, M. Ishida, T. Nakajima, Y. Honda, O. Kitao, H. Nakai, T. Vreven, J. Montgomery, J. Peralta, F. Ogliaro, M. Bearpark,; J. Heyd, E. Brothers, K. Kudin, V. Staroverov, R. Kobayashi, J. Normand, K. Raghavachari, A. Rendell, J. Burant, S. Iyengar, J. Tomasi, M. Cossi, N. Rega, N. Millam, M. Klene, J. Knox, J. Cross, V. Bakken, C. Adamo, J. Jaramillo, R. Gomperts, R. Stratmann, O. Yazyev, A. Austin, R. Cammi, C. Pomelli, J. Ochterski, R. Martin, K. Morokuma, V. Zakrzewski, G. Voth, P. Salvador, J. Dannenberg, S. Dapprich, A. Daniels, Ö. Farkas, J. Foresman, J. Ortiz, J. Cioslowski, D. Fox, Gaussian 09, Revision A. 02, Gaussian, Inc., Wallingford, CT 200 (2009).

[42] A. Bergner, M. Dolg, W. Küchle, H. Stoll, H. Preuß, Ab initio energy-adjusted pseudopotentials for elements of groups 13-17, Mol. Phys. 80 (1993) 1431-1441.

[43] Y. Nishibayashi, S. Iwai, M. Hidai, Bimetallic system for nitrogen fixation: ruthenium-assisted protonation of coordinated N2 on tungsten with H2, Science 279 (1998) $540-542$. 
[44] Y. Nishibayashi, S. Takemoto, S. Iwai, M. Hidai, Formation of ammonia in the reactions of a tungsten dinitrogen with ruthenium dihydrogen complexes under mild reaction conditions, Inorg. Chem. 39 (2000) 5946-5957.

[45] A.V. Marenich, C.J. Cramer, D.G. Truhlar, Universal solvation model based on solute electron density and on a continuum model of the solvent defined by the bulk dielectric constant and atomic surface tensions, J. Phys. Chem. B 113 (2009) 6378-6396.

[46] J. Tomasi, B. Mennucci, R. Cammi, Quantum mechanical continuum solvation models, Chem. Rev. 105 (2005) 2999-3094.

[47] W. Thimm, C. Gradert, H. Broda, F. Wennmohs, F. Neese, F. Tuczek, Free Reaction Enthalpy Profile of the Schrock Cycle Derived from Density Functional Theory Calculations on the Full [Mo(HIPT)N3N] Catalyst, Inorg. Chem. 54 (2015) 9248-9255.

[48] A.L. Colebatch, R.L. Cordiner, A.F. Hill, K.T.H.D. Nguyen, R. Shang, A.C. Willis, A Bis-Carbyne (Ethanediylidyne) Complex via the Catalytic Demercuration of a Mercury

Bis(carbido) Complex, Organometallics 28 (2009) 4394-4399.

[49] I.A. Cade, A.F. Hill, C.M.A. McQueen, Iridium-Molybdenum Carbido Complex via C-Se Activation of a Selenocarbonyl Ligand: $(\mu-\operatorname{Se} 2)[\operatorname{Ir} 2\{\mathrm{C} \equiv \mathrm{Mo}(\mathrm{CO}) 2(\mathrm{Tp} *)\} 2(\mathrm{CO}) 2(\mathrm{PPh} 3) 2]\left(\mathrm{Tp}^{*}=\right.$ hydrotris(dimethylpyrazolyl)borate), Organometallics 28 (2009) 6639-6641.

[50] H.A. Alturaifi, J. Faulkner, J. Raftery, F. Tuna, D. Collison, M.W. Whiteley, Synthesis and redox chemistry of cycloheptatrienyl molybdenum carbon-chain complexes featuring diimine support ligands: $\left.\mathrm{Mo}\{(\mathrm{CC}) \mathrm{nCCR}\}\left(\mathrm{R}^{\prime} \mathrm{NCH}-\mathrm{CHNR}^{\prime}\right)(\eta-\mathrm{C} 7 \mathrm{H} 7)\right],(\mathrm{n}=0$ or 1), J. Org. Chem. 745-746 (2013) 251-257.

[51] M. Bergeler, G.N. Simm, J. Proppe, M. Reiher, Heuristics-Guided Exploration of Reaction Mechanisms, J. Chem. Theory Comput. 11 (2015) 5712-5722.

[52] S. Schenk, B. Kirchner, M. Reiher, A stable six-coordinate intermediate in ammonia-dinitrogen exchange at Schrock's molybdenum catalyst, Chem. Eur. J. 15 (2009) 5073-5082.

[53] M. Reiher, B. Le Guennic, B. Kirchner, Theoretical study of catalytic dinitrogen reduction under mild conditions, Inorg. Chem. 44 (2005) 9640-9642.

[54] G.T.K.K. Gunasooriya, A.P. van Bavel, H.P.C.E. Kuipers, M. Saeys, Key Role of Surface Hydroxyl Groups in C-O Activation during Fischer-Tropsch Synthesis, ACS Catal. (2016) 3660-3664.

[55] G.C. Stephan, C. Sivasankar, F. Studt, F. Tuczek, Energetics and mechanism of ammonia synthesis through the Chatt Cycle: conditions for a catalytic mode and comparison with the Schrock Cycle, Chem. Eur. J. 14 (2008) 644-652.

[56] F. Studt, F. Tuczek, Energetics and mechanism of a room-temperature catalytic process for ammonia synthesis (Schrock cycle): comparison with biological nitrogen fixation, Angew. Chem. Int. Ed. 44 (2005) 5639-5642.

[57] N. Khoenkhoen, B. de Bruin, J.N.H. Reek, W.I. Dzik, Reactivity of Dinitrogen Bound to Mid- and Late-Transition-Metal Centers, Eur. J. Inorg. Chem. 2015 (2015) 567-598.

[58] R.R. Schrock, Catalytic reduction of dinitrogen to ammonia by molybdenum: theory versus experiment, Angew. Chem. Int. Ed. 47 (2008) 5512-5522.

[59] H. Tanaka, Y. Nishibayashi, K. Yoshizawa, Interplay between Theory and Experiment for Ammonia Synthesis Catalyzed by Transition Metal Complexes, Acc. Chem. Res. 49 (2016) 987-995. 
[60] A.E. Reed, R.B. Weinstock, F. Weinhold, Natural population analysisa), J. Chem. Phys. 83 (1985) 735.

[61] S. Schenk, M. Reiher, Ligands for dinitrogen fixation at Schrock-type catalysts, Inorg. Chem. 48 (2009) 1638-1648.

[62] W.W. Weare, X. Dai, M.J. Byrnes, J.M. Chin, R.R. Schrock, P. Muller, Catalytic reduction of dinitrogen to ammonia at a single molybdenum center, Proc. Natl. Acad. Sci. 103 (2006) 17099-17106.

[63] F. Neese, The Yandulov/Schrock cycle and the nitrogenase reaction: pathways of nitrogen fixation studied by density functional theory, Angew. Chem. Int. Ed. 45 (2005) 196-199. 


\section{Graphical abstract}

Chain-like extension of Nishibayashi's bimetallic structure was found to drastically enhance the catalytic performance of Mo-complexes for $\mathrm{N}_{2}$ to $\mathrm{NH}_{3}$ conversion. With proper bridging ligand like $[: \mathrm{C} \equiv \mathrm{C}:]^{2-}$, the polynuclear Mo-complexes can mediate the catalytic reaction to proceed facilely in a linear fashion on the energy profile sliding down from a high $\left(\mathrm{N}_{2}\right)$ to a low potential $\left(\mathrm{NH}_{3}\right)$.

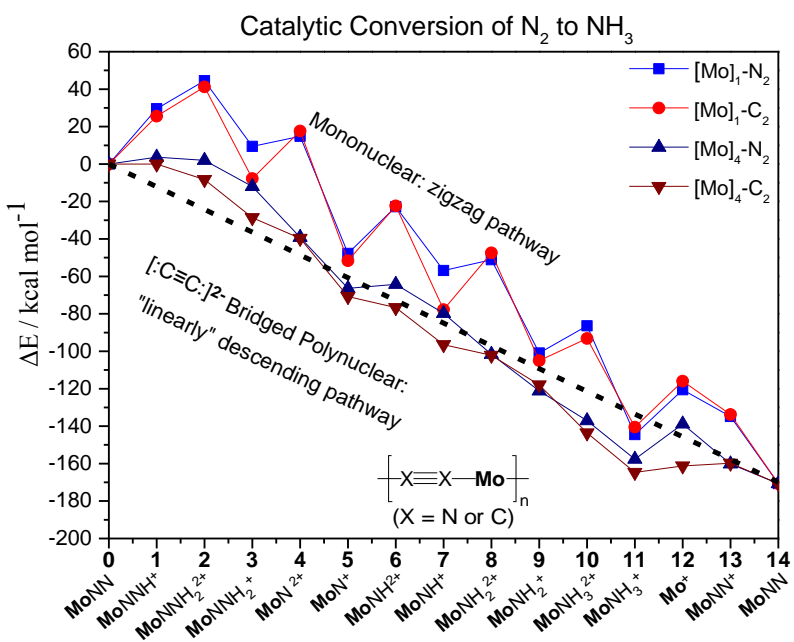

